Document downloaded from:

http://hdl.handle.net/10251/59881

This paper must be cited as:

Benavente Martínez, R.; Salvador Moya, MD.; Penaranda-Foix, FL.; Pallone, E.; Borrell Tomás, MA. (2014). Mechanical properties and microstructural evolution of alumina-zirconia nanocomposites by microwave sintering. Ceramics International. 40(7, Part B):11291-11297. doi:10.1016/j.ceramint.2014.03.153.

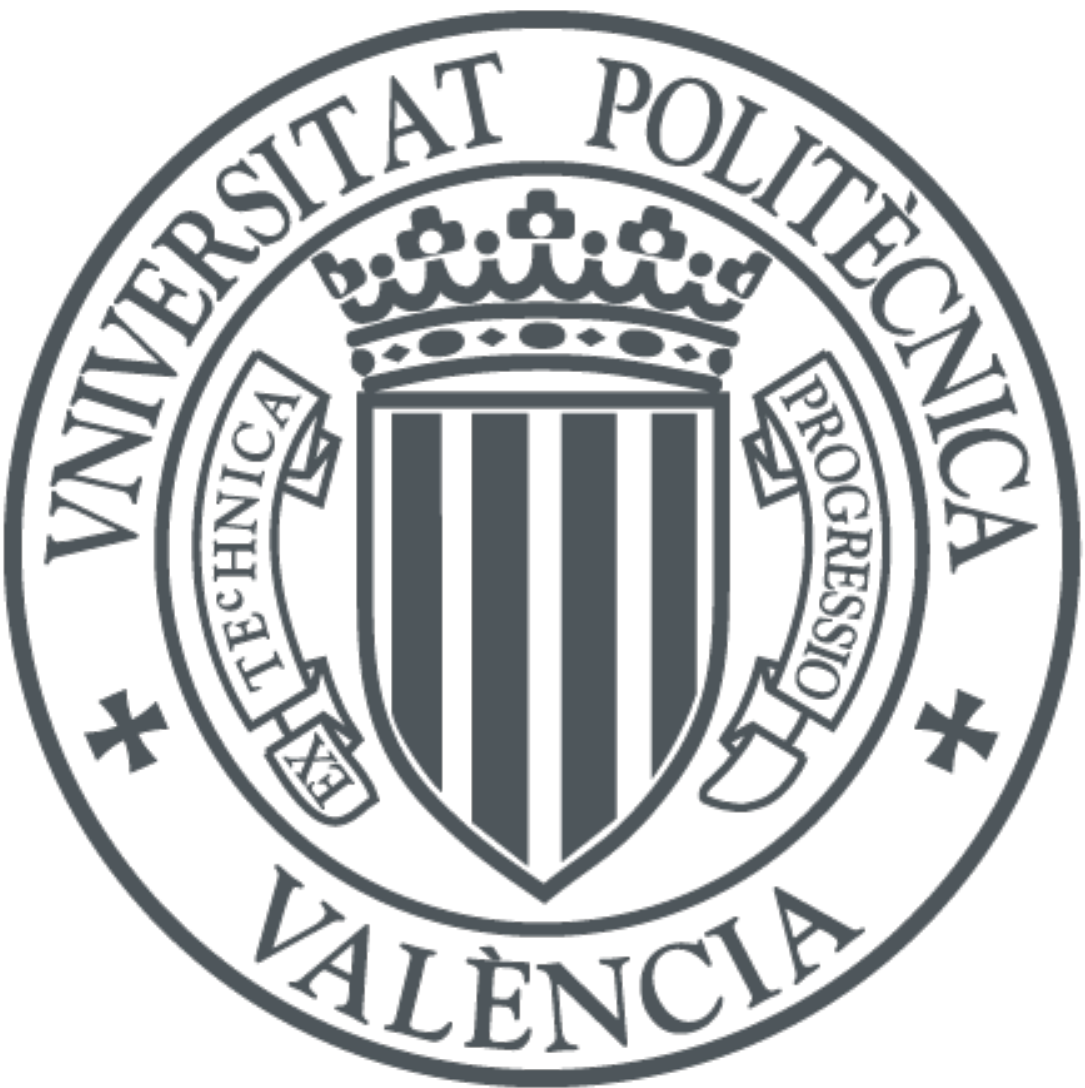

The final publication is available at

http://dx.doi.org/10.1016/j.ceramint.2014.03.153

Copyright Elsevier

Additional Information 


\title{
Mechanical properties and microstructural evolution of
}

\section{alumina-zirconia nanocomposites by microwave sintering}

\section{R. Benavente ${ }^{1 *}$, M. D. Salvador ${ }^{1}$, F. L. Penaranda-Foix ${ }^{2}$, E. Pallone ${ }^{3}$, A. Borrell ${ }^{1}$}

${ }^{1}$ Instituto de Tecnología de Materiales (ITM), Universitat Politècnica de València, Camino de Vera, s/n, 46022 Valencia, Spain

${ }^{2}$ Instituto de Aplicaciones de las Tecnologías de la Información y de las

Comunicaciones Avanzadas (ITACA), Universitat Politècnica de València, Camino de Vera, s/n, 46022 Valencia, Spain

${ }^{3}$ Universidade de São Paulo-FZEA, Avenida Duque Caxias Norte 225, 13635-900 Pirassununga, SP, Brasil

*Corresponding author. Address: Instituto de Tecnología de Materiales (ITM), Universidad Politécnica de Valencia (UPV), Camino de Vera s/n, 46022 Valencia, Spain. Tel.: +34963877007; Fax: +34963877629 .

E-mail address: rutbmr@upvnet.upv.es (R. Benavente)

\begin{abstract}
Microwave sintering has emerged in recent years as a novel method for sintering a variety of materials that have shown significant advantages against conventional sintering procedures. This work involved an investigation of microwave hybrid fast firing of alumina-zirconia nanocomposites using commercial alumina powder and monoclinic nanometric zirconia. The suspensions were prepared separately in order to obtain 5,10 and 15 vol.\% of $\mathrm{ZrO}_{2}$ in the alumina matrix. The samples were sintered in a
\end{abstract}


monomode microwave furnace at $2.45 \mathrm{GHz}$ in air at different temperatures in the range $1200-1400{ }^{\circ} \mathrm{C}$ with $10 \mathrm{~min}$ of dwelling time and $200{ }^{\circ} \mathrm{C} / \mathrm{min}$ of heating rate. The effect of sintering temperature in densification, mechanical properties and microstructure behaviour of the composites was investigated.

Higher density, hardness and Young's modulus, excellent fracture toughness properties and homogeneous microstructure were achieved by microwave sintering in comparison to conventional heating. Microstructure analysis showed that the alumina grains had not grown significantly, indicating that the zirconia particles provided a hindering effect on the grain growth of alumina.

Keywords: Alumina-zirconia nanocomposites; Microwave sintering; Mechanical properties; Microstructure

\section{Introduction}

Alumina-zirconia nanocomposites are considered among advanced ceramics due to their superior mechanical properties and chemical inertness, and they have been used for wide range of applications such as biomedical implants [1,2] and structural ceramics $[3,4]$. One of the main reasons for improving mechanical behavior is the ability of transformation toughening which usually is induced by applied stresses to the composite structure $[5,6]$.

Recent studies suggest that mechanical properties of $\mathrm{Al}_{2} \mathrm{O}_{3}-\mathrm{ZrO}_{2}$ composites could be considerable increased by reducing level of grain size and increasing dispersion. $\mathrm{Al}_{2} \mathrm{O}_{3}$ $\mathrm{ZrO}_{2}$ composites with high transformation toughening can be obtained if a amount of tetragonal phase with the ability to transform under applied stress is retained at room 
temperature $[7,8]$. To meet this requirement, the size of zirconia grain must be smaller than a critical size $(0.7 \mu \mathrm{m})$ to ensure the stability of tetragonal phase at room temperature [9-11]. A fine-grained $\mathrm{Al}_{2} \mathrm{O}_{3}$ matrix also results in enhanced mechanical properties. Furthermore, it is suggested that a smaller matrix size (grain at submicron level or nanoscale) will result in a higher improvement in mechanical properties. Therefore, dense fine-grained and full-dense $\mathrm{Al}_{2} \mathrm{O}_{3}-\mathrm{ZrO}_{2}$ composites are desirable to be achieved [10-12]. Unfortunately, it is difficult to obtain $\mathrm{Al}_{2} \mathrm{O}_{3}-\mathrm{ZrO}_{2}$ composites with high density and smaller grain size with conventional techniques. This is mainly due to the inevitable grain growth during the sintering process. In addition, the low heating rate used in conventional sintering processes requires a long heating step from room temperature to the target sintering temperature, which results in the coarsening of the nanoparticles [13]. To minimize grain growth and to enhance mechanical properties, microwave sintering has been proposed. This fast sintering technique is regarded as a promising method to inhibit grain growth because of short sintering duration [14-18]. The significant difference between conventional sintering and microwave fast sintering is the heating rate and the heating mode. Microwave sintering method is a fastest consolidation technique with a low energetic cost $[15,17]$. The heating mode is a parameter that strongly influences the final density and microstructure of the materials obtained from nanometric powders. It is suggested that the combination of a fast heating rate and a non-conventional heating is a promising mean to obtain full-density materials [19].

This work shows the design of a rectangular cavity, based on the $\mathrm{TE}_{101}$ mode, including a control system to follow a temperature profile to obtain $\mathrm{Al}_{2} \mathrm{O}_{3}-\mathrm{ZrO}_{2}$ nanocomposites. Therefore, this work studies, on one hand, the general effect of microwave heating on 
the sintering procedure of $\mathrm{Al}_{2} \mathrm{O}_{3}-\mathrm{ZrO}_{2}$ nanocomposites and, on the other hand, reveals the major contribution of high heating rates on the microstructural improvement and the mechanical properties of microwave-sintered samples. A comparison between the conventional sintering is also represented within the results.

\section{Methods And Materials}

\section{A. Microwave cavity}

Fig 1 shows the system designed to sinter the materials. From right to left are displayed: the $1 \mathrm{~kW}$ magnetron, including the feeding system, the circulator to prevent the power source from reflected power (including a coupling system to measure the reflected power with the multimeter), the $\mathrm{TE}_{101}$ cavity, which will be described in detail in the next paragraphs, and a motorized short-circuit to tune the cavity and connected to a laptop to allow an automatic tuning system. The rectangular cavity excites the $\mathrm{TE}_{101}$ mode, based on a WR340 waveguide and excited through a circular iris to maximize the $\mathrm{H}_{\mathrm{x}}$ magnetic component of the $\mathrm{TE}_{101}$ mode.

The sample is introduced in the cavity through an insertion hole located approximately in the center of the cavity (the cavity dimensions can vary with the motorized shortcicuit) and on the top of it. The insertion hole has a diameter of $3 \mathrm{~cm}$ to guarantee that the insertion hole is under cut-off and no microwave energy leakage through it with the $\mathrm{TE}_{11}$ mode, which is the fundamental mode in the cylindrical waveguide.

In the center of the cavity the excited mode has a maximum of $E_{y}$ component, and a behavior of a $\sin (\cdot)^{2}$ in the axial component and no variation in the vertical component, 
which guarantees the homogeneity of the field in the sample, which is supposed to be about $1 \mathrm{~cm}$ of diameter as maximum.

To locate the sample in the center, a quartz tube is used, which is transparent to the microwave energy. This could be also used for introducing different atmosphere (or even vacuum). To monitorize the temperature, a pyrometer is located on the top, as shown in Fig. 1. This allows to include a control system to automatize the heating process, based on a PID system.

A close scheme of the cavity is shown in the Fig. 1 (right), where the position of the sample is shown and also the sliding short circuit that changes the resonant frequency of the cavity and is controlled by the PID to guarantee the tuning of the cavity.

\section{B. Experimental procedure}

Raw materials used for the preparation of the nanocomposites were commercial alumina AKP-53 provided by Sumitomo Co., Japan (purity 99.99\%, with mean particle diameter of $200 \mathrm{~nm}$ and $3.95 \mathrm{~g} \cdot \mathrm{cm}^{-3}$ density), and nanometric zirconia (purity $99.99 \%$, monoclinic, primary sized particles from $60-100 \mathrm{~nm}$ and $5.98 \mathrm{~g} \cdot \mathrm{cm}^{-3}$ density) provided by Nanostructured Materials, Inc. The procedure of dispersing the zirconia powder in the $\mathrm{Al}_{2} \mathrm{O}_{3}$ powder involves the preparation 5, 10 and 15 vol.\% of $\mathrm{ZrO}_{2}$ suspension through traditional milling (A5Z, A10Z and A15Z, respectively). Cylindrical specimens with 10 $\mathrm{mm}$ diameter and about $5 \mathrm{~mm}$ height were prepared, by cold isostatic pressing (200 $\mathrm{MPa})$.

Green samples were sintered under air by microwave technology at 1200, 1300 and 1400 
${ }^{\circ} \mathrm{C}$ using the heating rate of $200{ }^{\circ} \mathrm{C} / \mathrm{min}$ with 10 -min of holding time at the maximum temperature. $\mathrm{SiC}$ was selected as a microwave susceptor to assist heating and sintering of the green samples. The temperature of the sample was monitored by an infrared radiation thermometer (Optris CT-Laser LT, 8-14 um), which is focused on the test sample via the small circular aperture in the wall of the test cell. For comparison, the same green compacts were conventionally sintered at $1400^{\circ} \mathrm{C}$ using the heating rate of $10{ }^{\circ} \mathrm{C} / \mathrm{min}$ with $2 \mathrm{~h}$ of holding time at the maximum temperature.

The bulk density of the sintered samples was measured following Archimedes' principle by immersing the sample into water based liquid (ASTM C373-88).

Vickers hardness and fracture toughness assessments were carried out using the indentation method. Sintered samples were longitudinally cut in half cylinders with a diamond saw. Before the test samples were polished (Struers, model RotoPol-31) with diamond to $1 \mu \mathrm{m}$ roughness. The hardness of the materials was determined using the indentation technique (Buehler, model Micromet 5103) with a conventional diamond pyramid indenter. The diagonals of each indentation were measured using an optical microscope. Measuring conditions for the Vickers hardness, $H_{v}$, were an applied load of $5 \mathrm{~N}$ for $10 \mathrm{~s}$ and the standard specification ASTM E92-72. The value of $H_{v}$ is the relationship between applied load $P$ and the surface area of the diagonals of indentation [20]. To estimate the indentation fracture toughness $K_{I C}, 306 \mathrm{~N}$, Vickers indentations were performed on the surface of the samples, inducing Palmqvist cracks, from which the indentation fracture toughness was obtained by the method of Niihara [21]. 
Young's modulus of samples was obtained by nanoindentation technique (Model G200, MTS Company, USA) with a Berkovich diamond tip. The tests were performed under depth control with $2000 \mathrm{~nm}$ of maximum depth. Data were evaluated from the loaddisplacement nanoindentation data using the widely accepted Oliver and Pharr model [22].

In order to analyse sample microstructure, polished sections were thermally etched between $10 \mathrm{~min}$ in an electrical furnace under air $200{ }^{\circ} \mathrm{C}$ below their maximum sintering temperature. These sections have been observed using a field emission scanning electron microscope (FEG-SEM, S4800 HITACHI, SCSIE of the University of Valencia). The grain size of the sintered samples was determined by multiplying the average linear intercept by 1.56 [23]. For each specimen, at least 15 lines were taken, and their average was reported.

\section{Results And Discussion}

\subsection{Final density and microstructure}

The final relative density values of the $\mathrm{Al}_{2} \mathrm{O}_{3}-5,10$ and 15 vol.\% $\mathrm{ZrO}_{2}(\mathrm{~A} 5 \mathrm{Z}, \mathrm{A} 10 \mathrm{Z}$ and A15Z, respectively) composites sintered by the microwave (MW) process are presented in Figure 2, as a function of their maximum sintering temperature.

The relative density values of the A5Z, A10Z and A15Z composites obtained by conventional sintering (CS) at $1400{ }^{\circ} \mathrm{C}$ is $97.2 \%, 97.5 \%$ and $97.8 \%$, respectively.

As seen in Fig. 2, the relative density was a linear function of the sintering temperature as expected. The relative densities increased steadily from 89 to $99 \%$ with increasing sintering temperature. 
Concerning the results of microwave sintering, the first significant outcome of Fig. 2 is that the density values of a microwave-sintered material are higher than the density of a material conventionally sintered at the same temperature.

At low temperatures $\left(1200\right.$ and $\left.1300{ }^{\circ} \mathrm{C}\right)$ the final density of the microwave-sintered composites depends on the percentage of the zirconia material, as increasing the amount of $\mathrm{ZrO}_{2}$ from 5 to $15 \mathrm{vol} \%$, the relative density values obtained are higher. This is due to the fact that zirconia powders sinter at lower temperatures in relation to alumina powders [24].

It is important to note that there is a faster increase of densification for the samples with a lower $\mathrm{ZrO}_{2}$ content (5 and 10 vol.\%), when the temperatures increase from 1300 to $1400{ }^{\circ} \mathrm{C}(6 \%$ and $4 \%$, respectively). It can be seen that all samples sintered by MW at $1400{ }^{\circ} \mathrm{C}$ show very similar densities ( $>99 \%$ ), regardless of the zirconia percentage. At this temperature the composites achieve the maximum density values due to the fact that all grains are close to their maximum compaction.

This is similar to the results of the $\mathrm{Al}_{2} \mathrm{O}_{3}-\mathrm{ZrO}_{2}$ composites studied by $\mathrm{Ye}$, Meng and Yang et al. $[12,25,26]$. In the results obtained by $\mathrm{Ye}$ et al. [12], $\mathrm{ZrO}_{2}$ nanoparticles could be uniformly dispersed in $\mathrm{Al}_{2} \mathrm{O}_{3}$ matrix when its percentage was less than 20 wt.\%, as the homogeneous dispersion of $\mathrm{ZrO}_{2}$ nanoparticles could effectively restrain the abnormal growth of $\mathrm{Al}_{2} \mathrm{O}_{3}$ grains, and therefore, $\mathrm{ZrO}_{2}$ nanoparticles can accelerate densification of samples under this circumstance. However, when its percentage was over 20 wt.\%, $\mathrm{ZrO}_{2}$ nanoparticles could not be uniformly dispersed in $\mathrm{Al}_{2} \mathrm{O}_{3}$ matrix. The inhomogeneous dispersion of $\mathrm{ZrO}_{2}$ nanoparticles in $\mathrm{Al}_{2} \mathrm{O}_{3}$ matrix could form large pores and a higher temperature is necessary to eliminate the pores and form dense 
bodies, which could cause the abnormal growth of $\mathrm{Al}_{2} \mathrm{O}_{3}$ grains and lead to expansion until cracking, causing a decrease in the relative densities, strength and fracture toughness of samples.

Menezes et al. [27] also studied the effects of the contents of 1, 3 and 5 vol. $\%$ of $\mathrm{ZrO}_{2}$ on the sintering densification and microstructure of the $\mathrm{Al}_{2} \mathrm{O}_{3}-\mathrm{ZrO}_{2}$ by a microwave hybrid process. The samples containing 5 vol.\% of zirconia presented low density (97.5\%) after $30 \mathrm{~min}$ of heating, but their density increased significantly with sintering time, reaching a high density level after $35 \mathrm{~min}$ of heating $(99.0 \%)$.

At the same time, spark plasma sintering process (SPS) is shown to be a highly efficient technique for densification of fine-grained $\mathrm{Al}_{2} \mathrm{O}_{3}-\mathrm{ZrO}_{2}$ composites at temperatures 100 $200{ }^{\circ} \mathrm{C}$ lower than that needed by conventional sintering. This reduction in sintering temperature is attributed to the high pressure used $(100 \mathrm{MPa})$ and the efficient heat transfer from spark discharge between the particles [13]. But this method has a big problem with the sintering of zirconia materials compared with microwave processing due to carbon diffusion within the zirconia sample by SPS, which is linked to the carbon rich atmosphere in which it is performed [15]. As the sintering of the compact is taking place in a graphite die, the carbon diffuses into the sample from the die and this process is affected by the applied pressure. The sample sintered by SPS shows a full black colour. Eliminating this contamination is possible, but this would require high temperatures $\left(>800^{\circ} \mathrm{C}\right)$ and a long time inside a furnace $(>2 \mathrm{~h})$, resulting in high economic costs.

The FE-SEM micrographs of the alumina-zirconia ceramics prepared by microwave and conventional sintering are shown in Fig. 3 and 4, respectively. There is obvious 
microstructure difference for the alumina-zirconia ceramics prepared by microwave and pressure-less or conventional sintering.

Fig. 3 shows the fully dense microstructure of microwave sintered samples and the smaller zirconia grains homogeneously dispersed in alumina matrix. This result is in agreement with the relative density data given in Fig. 2. During sintering, finely dispersed zirconia particles delay the motion of alumina grain boundaries, which inhibit the grain growth of alumina [28].

As shown in Fig. 3, all sintered samples have a similar grain size. Small differences in MW process samples are shown as $\mathrm{ZrO}_{2}$ content increase. The average grain size of $\mathrm{Al}_{2} \mathrm{O}_{3}$ and $\mathrm{ZrO}_{2}$ in the specimen sintered at $1400{ }^{\circ} \mathrm{C}$ with 5 and 10 vol.\% $\mathrm{ZrO}_{2}$ reaches about 420 and $125 \mathrm{~nm}$, respectively (Fig. 3a and 3b). While samples sintered at $1400{ }^{\circ} \mathrm{C}$ with 15 vol. $\% \mathrm{ZrO}_{2}$ yield a grain size of 575 and $146 \mathrm{~nm}$, respectively (Fig. 3c). The final grain size of $\mathrm{Al}_{2} \mathrm{O}_{3}$ is smaller when the $\mathrm{ZrO}_{2}$ content is lower (5 and 10 vol.\%). A limited amount of zirconia grains were located at the boundaries of alumina grains, and most of them are present at triple junctions, resulting in an intergranular type nanocomposite.

The evolution of average grain size of the conventionally sintered specimens is similar to the microwave samples (Fig. 4). Therefore, the main parameter governing grain growth is the $\mathrm{ZrO}_{2}$ content. With a lower content of $\mathrm{ZrO}_{2}$ (A5Z and $\left.\mathrm{A} 10 \mathrm{Z}\right)$, the average grain size of $\mathrm{Al}_{2} \mathrm{O}_{3}$ and $\mathrm{ZrO}_{2}$ reaches about 570 and $160 \mathrm{~nm}$, respectively (Fig. 4a and 4b). But in the $\mathrm{A} 15 \mathrm{Z}$ sample, the average grain size of $\mathrm{Al}_{2} \mathrm{O}_{3}$ and $\mathrm{ZrO}_{2}$ reaches about 928 and $196 \mathrm{~nm}$, respectively (Fig. 4c). Therefore, this data show larger grain sizes in samples sintered by conventional process with high $\mathrm{ZrO}_{2}$ content, this behaviour suggesting that the microwaves had direct effect on cation segregation at the grain 
boundaries during the phase partitioning process, which is known to be responsible for the sluggish grain growth during the final stage of sintering [29].

\subsection{Hardness and fracture toughness}

Vickers hardness, fracture toughness and Young's modulus of microwave fabricated $\mathrm{Al}_{2} \mathrm{O}_{3}-\mathrm{ZrO}_{2}$ materials are presented in Fig. 5, 6 and 7, respectively, as a function of final sintering temperature.

The Vickers hardness values of the A5Z, A10Z and A15Z composites obtained by conventional sintering $(\mathrm{CS})$ at $1400{ }^{\circ} \mathrm{C}$ are $16.4,17.1$ and $16.5 \mathrm{GPa}$, respectively. As can be seen in Fig. 5, the measurements show that the hardness values increase with the density data and also, increase slightly with decreasing $\mathrm{ZrO}_{2}$ content.

Previous studies [30] have reported Vickers microhardness of sintered $\mathrm{ZrO}_{2}(3 \mathrm{Y})+20 \mathrm{wt} . \% \quad \mathrm{Al}_{2} \mathrm{O}_{3}$ with micrometer grain size $(20 \mu \mathrm{m})$. These full-dense specimens sintered by SPS presented a hardness value of $12.6 \mathrm{GPa}$ at $1400{ }^{\circ} \mathrm{C}$. Usually, the Vickers microhardness of the $\mathrm{Al}_{2} \mathrm{O}_{3}-\mathrm{ZrO}_{2}$ ceramics with micro-nano structure is 14$15 \mathrm{GPa}$ [31]. Meng et at. [24] found Vickers microhardness value of $19.5 \mathrm{GPa}$ with 10 wt. $\%$ of $\mathrm{ZrO}_{2}$ material sintered by SPS at $1400{ }^{\circ} \mathrm{C}$, whereas in our present work, at same temperature, the A10Z sample with submicro-nanostructure has around $20 \mathrm{GPa}$ of microhardness. This is mostly attributed to the submicro-nanostructure and high density of the A10Z sample.

In the CS samples at $1400{ }^{\circ} \mathrm{C}$, the values are close to $\sim 17 \mathrm{GPa}$ and the samples by MW method with 5 and 15 vol.\% of $\mathrm{ZrO}_{2}$ show values $\sim 18 \mathrm{GPa}$. The maximum hardness 
achieved is for the A10Z sample sintered by MW at $1400{ }^{\circ} \mathrm{C}$. Therefore, the highest level of hardness belonged to the specimens sintered by the MW method. This is due to the better and faster densification of the MW-sintered specimens and corresponding smaller grain sizes. The authors haven't found values of hardness and toughness of the $\mathrm{Al}_{2} \mathrm{O}_{3}-\mathrm{ZrO}_{2}$ composites sintered by microwave process reported in the literature so far.

The fracture toughness values of the A5Z, A10Z and A15Z composites obtained by conventional sintering (CS) at $1400{ }^{\circ} \mathrm{C}$ were $3.3,5.5$ and $5.8 \mathrm{MPa} \mathrm{m}^{1 / 2}$, respectively.

Shen et al. have reported fracture toughness of pure alumina sintered by SPS with submicron grain size with a value of $3.8 \mathrm{MPa} \mathrm{m}^{1 / 2}$ [32]. Therefore, it has been shown that the presence of zirconia particles results in an improved toughness compared with pure $\mathrm{Al}_{2} \mathrm{O}_{3}$. At the same time, the fracture toughness of the composites increased with increasing volume fraction of $\mathrm{ZrO}_{2}$. Similar results of fracture toughness were also observed in the $\mathrm{ZrO}_{2}-\mathrm{Al}_{2} \mathrm{O}_{3}$ composites with a fine-grained structure [10]. The composite $\left(7.5\right.$ vol. $\% \mathrm{ZrO}_{2}$ ) obtained by the colloidal processing with a fine structure attained a fracture toughness value of 5.3 $\mathrm{MPa} \mathrm{m}^{1 / 2}$. Meng et al. found that the fracture toughness value of AZ5 and AZ10 obtained by SPS were 4.5 and $5.1 \mathrm{MPa} \mathrm{m}{ }^{1 / 2}$, respectively [24]. The maximum fracture toughness value achieved in the present study was for the $\mathrm{A} 15 \mathrm{Z}$ sample sintered by $\mathrm{MW}$ at $1400{ }^{\circ} \mathrm{C}, \sim 6 \mathrm{MPa} \mathrm{m}^{1 / 2}$. Therefore, this is an excellent value compared with others $\mathrm{ZrO}_{2}-\mathrm{Al}_{2} \mathrm{O}_{3}$ composites obtained with nonconventional sintering technique such as SPS. The toughness enhancement for all the composites investigated can be attributed to a transformation toughening effect and a high densification level achieved. 
Young's modulus (E) values of the A5Z, A10Z and A15Z composites obtained by conventional sintering (CS) at $1400{ }^{\circ} \mathrm{C}$ are 352,342 and $337 \mathrm{GPa}$, respectively. In all the cases, the samples obtained by microwaves sintering show higher Young's modulus values than the CS samples (Fig.7). These values increase simultaneously with the sintering temperature as well as hardness values. High density result in high values of Young's modulus, but this is not a linear relationship. Porosity, grain size, distribution of grains and pores are factors that also affect the values of E. The maximum E value achieved is with the $\mathrm{A} 10 \mathrm{Z}$ sample sintered by $\mathrm{MW}$ at $1400{ }^{\circ} \mathrm{C}(367 \mathrm{GPa})$.

Therefore, microwave technology has been demonstrated a fast consolidation process with very low power consumption. The short heating-cooling time of MW (30 min) compared with the long processing time $(\sim 12 \mathrm{~h})$ for $\mathrm{CS}$, sets important advantages on the industrial application of this method as an advanced process for new technological challenges.

To summarize, the mechanical properties and final microstructure of $\mathrm{ZrO}_{2}-\mathrm{Al}_{2} \mathrm{O}_{3}$ ceramics were greatly dependent on the final temperature, $\mathrm{ZrO}_{2}$ content and sintering technique. Furthermore, the particle size and the distribution of the second phase also played an important role in influencing the densification behavior and the mechanical properties. It has been proven that it is possible to obtain $\mathrm{ZrO}_{2}-\mathrm{Al}_{2} \mathrm{O}_{3}$ composites with excellent mechanical properties using microwave method.

\section{Conclusions}

Sintering behaviour of $\mathrm{Al}_{2} \mathrm{O}_{3}-\mathrm{ZrO}_{2}$ nanopowder compacts is investigated in the present study using conventional and microwave-assisted sintering. This device included an 
optical pyrometer with an emissivity perfectly calibrated for measuring the temperature of the top surface of the materials. Using this device we achieved a fine control of the heating rate, final temperature and holding time desired.

Concerning microstructure changes, our results proved that the grain size was dependent on the maximum sintering temperature achieved and $\mathrm{ZrO}_{2}$ percentage. However, due to the positive effect of microwaves on the densification, the material showed a slightly smaller grain size when compared to the grain size achieved by conventional heating.

Hardness, Young's modulus and fracture strength values for $\mathrm{Al}_{2} \mathrm{O}_{3}-\mathrm{ZrO}_{2}$ materials obtained by microwave are being reported for the first time. Microwave sintered $\mathrm{Al}_{2} \mathrm{O}_{3}$ $\mathrm{ZrO}_{2}$ materials exhibited superior mechanical property values when compared with conventional fired materials, as was expected from their higher densities. The excellent fracture toughness increase with $\mathrm{ZrO}_{2}$ content and the highest value is reached with the A15Z sample, $6 \mathrm{MPa} \mathrm{m}{ }^{1 / 2}$. The sample with 10 vol. $\% \mathrm{ZrO}_{2}$ content has the maximum hardness and Young's modulus values (20 and $367 \mathrm{GPa}$, respectively).

\section{Acknowledgement}

The authors would like to thank of the Polytechnic University of Valencia (UPV) for financial support received for projects SP20120621, SP20120398 and SP20120677 and Spanish Government (TEC2012-37532-C02-01). A. Borrell, acknowledges the Spanish Ministry of Science and Innovation for her Juan de la Cierva contract (JCI-2011-10498) and Generalitat Valenciana by Gerónimo Forteza funding (FPA/2012/022). 


\section{REFERENCES}

[1] Z.G. Liu, J.H Ouyang, Y. Zhou, J. Li, Effect of alumina addition on the phase evolution and thermal conductivity of $\mathrm{ZrO}_{2}-\mathrm{NdO}_{1.5}$ ceramics, Journal of Alloys and Compounds 468 (2009) 350-355.

[2] R. Benzaid, J. Chevalier, M. Saadaoui, G. Fantozzi, M. Nawa, L.A. Diaz, R. Torrecillas, Fracture toughness, strength and slow crack growth in a ceria stabilized zirconia-alumina nanocomposite for medical applications, Biomaterials 29 (2008) 36363641, 2008.

[3] J. Chandradass, M.H. Kim, D.S. Bae, Influence of citric acid to aluminium nitrate molar ratio on the combustion synthesis of alumina-zirconia nanopowders, Journal of Alloys and Compounds 470 (2009) 9-12.

[4] Z. Wei, H. Li, X. Zhang, S. Yan, Z. Lv, Y. Chen, M. Gong, Preparation and property investigation of $\mathrm{CeO}_{2}-\mathrm{ZrO}_{2}-\mathrm{Al}_{2} \mathrm{O}_{3}$ oxygen-storage compounds, Journal of Alloys and Compounds 455 (2008) 322-326.

[5] Z. Xiu, J. Laeng, X. Sun, Q. Li, S.K. Hur, Y. Liu, Phase formation of $\mathrm{Al}_{2} \mathrm{O}_{3} / \mathrm{Ti}(\mathrm{C}, \mathrm{N})-\mathrm{NiTi}$ composite, Journal of Alloys and Compounds 458 (2008) 398-404. [6] A.Z.A. Azhar, M.M. Ratnam, Z.A. Ahmad, Effect of $\mathrm{Al}_{2} \mathrm{O}_{3} / \mathrm{YSZ}$ microstructures on wear and mechanical properties of cutting inserts, Journal of Alloys and Compounds 478 (2009) 608-614.

[7] C.J. Wang, C.Y. Huang, Y.C. Wu, Two-step sintering of fine alumina-zirconia ceramics, Ceramics International 35 (2009) 1467-1472.

[8] W.H. Tuan, R.Z. Chen, T.C. Wang, C.H. Cheng, P.S. Kuo, Mechanical properties of $\mathrm{Al}_{2} \mathrm{O}_{3} / \mathrm{ZrO}_{2}$ composites, Journal of the European Ceramic Society 22 (2002) 2827-2833. [9] J.R. Kelly, I. Denry, Stabilized zirconia as a structural material, Dental Materials, 24 (2008) 289-298. 
[10] A.H. De Aza, J. Chevalier, G. Fantozzi, Slow-crack-growth behavior of zirconiatoughened alumina ceramics processed by different methods, Journal of the American Ceramic Society 86 (2003) 115-120.

[11] F.A.T. Guimaraes, K.L. Silva, V. Trombini, J.J. Pierri, J.A. Rodrigues, R. Tomasi, E.M. Pallone, Correlation between microstructure and mechanical properties of $\mathrm{Al}_{2} \mathrm{O}_{3} / \mathrm{ZrO}_{2}$ nanocomposites, Ceramics International 35 (2009) 741-745.

[12] Y.P. Ye, J.G. Li, H.D. Zhou, J.M. Chen, Microstructure and mechanical properties of yttria-stabilized $\mathrm{ZrO}_{2} / \mathrm{Al}_{2} \mathrm{O}_{3}$ nanocomposite ceramics, Ceramics International 34 (2008) 1797-1803.

[13] Z.A. Munir, U. Anselmi-Tamburini, M. Ohyanagi, The effect of electric field and pressure on the synthesis and consolidation of materials: A review of the spark plasma sintering method, Journal of Materials Science 41 (2006) 763-777.

[14] J. Binner, K. Annapoorani, A. Paul, I. Santacruz, B. Vaidhyanathan, Dense nanostructured zirconia by two stage conventional/hybrid microwave sintering, Journal of the European Ceramic Society 28 (2008) 973-977.

[15] A. Borrell, M.D. Salvador, E. Rayón, F.L. Peñaranda-Foix, Improvement of microstructural properties of 3Y-TZP materials by conventional and non-conventional sintering techniques, Ceramics International 38 (2012) 39-43.

[16] A. Borrell, M.D. Salvador, F.L. Peñaranda-Foix, J.M. Catalá-Civera, Microwave sintering of zirconia materials: Mechanical and microstructural properties, International Journal of Applied Ceramic Technology 10 (2013) 313-320.

[17] R. Benavente, A. Borrell, M.D. Salvador, O. García-Moreno, F.L. Peñaranda-Foix, J.M. Catalá-Civera, Fabrication of near-zero thermal expansion of fully dense $\beta$ eucryptite ceramics by microwave sintering, Ceramics International 40 (2014) 935-941. 
[18] S. Oh, K. Tajima, M. Ando, T. Ohji, Fabrication of porous $\mathrm{Al}_{2} \mathrm{O}_{3}$ by microwave sintering and its properties, Materials Letters 48 (2001) 215-218.

[19] P. Figiel, M. Rozmus, B. Smuk, Properties of alumina ceramics obtained by conventional and non-conventional methods for sintering ceramics, Journal of Achievements in Materials and Manufacturing Engineering 48 (2011) 29-34.

[20] G. Antis, P. Chantikul, B. Lawn, D. Marshall, A Critical evaluation of indentation techniques for measuring fracture toughness: I, Direct crack measurements, Journal of the American Ceramic Society 64 (1981) 533-538.

[21] K. Niihara, R. Morena, D.P.H. Hasselman, Evaluation of $\mathrm{K}_{\mathrm{IC}}$ of brittle solids by the indentation method with low crack-to-indentation ratios, Journal of Materials Science Letter 1 (1982) 13-16.

[22] W.C. Oliver, G.M. Pharr, An improved technique for determining hardness and elastic modulus using load and displacement sensing indentation experiments, Journal of Materials Research 7 (1992) 1564-83.

[23] Y. Wang, Z. Fu, Study of temperature field in spark plasma sintering, Material Science Engineering B. 90 (2002) 34-37.

[24] W. Li, L. Gao, Rapid sintering of nanocrystalline $\mathrm{ZrO}_{2}(3 \mathrm{Y})$ by spark plasma sintering, Journal of the European Ceramic Society 20 (2000) 2441-2445.

[25] M. Fancheng, L. Cheng, Z. Fan, T. Zhongqing, H. Weijiu, Densification and mechanical properties of fine-grained $\mathrm{Al}_{2} \mathrm{O}_{3}-\mathrm{ZrO}_{2}$ composites consolidated by spark plasma sintering, Journal of Alloys and Compounds 512 (2012) 63-67.

[26] G. Yang, J.C. Li, G.C. Wang, M. Yashima, S.L. Min, Influences of $\mathrm{ZrO}_{2}$ nanoparticles on the microstructure and mechanical behavior of $\mathrm{Ce}-\mathrm{TZP} / \mathrm{Al}_{2} \mathrm{O}_{3}$ nanocomposites, Journal of Materials Science 40 (2005) 6087-6090.

[27] R.R. Menezes, R.H.G.A. Kiminami, Microwave sintering of alumina-zirconia 
nanocomposites, Journal of Material Processing Technology 203 (2008) 513-517.

[28] D. Sarkar, S. Adak, N.K. Mitra, Preparation and characterization of an $\mathrm{Al}_{2} \mathrm{O}_{3}-\mathrm{ZrO}_{2}$ nanocomposites, Part I: powder synthesis and transformation behavior during fracture, Composites Part A 38 (2007) 124-131.

[29] K. Matsui, H. Yoshida, Y. Ikuhara, Isothermal sintering effects on phase separation and grain growth in yttria-stabilized tetragonal zirconia polycrystal, Journal of the American Ceramic Society 92 (2009) 467-475.

[30] L. Shufeng, I. Hiroshi, O. Michiharu, Z. Weihua, W. Taku, Microstructure and mechanical properties of $\mathrm{ZrO}_{2}\left(\mathrm{Y}_{2} \mathrm{O}_{3}\right)-\mathrm{Al}_{2} \mathrm{O}_{3}$ nanocomposites prepared by spark plasma sintering, Particuology 10 (2012) 345-351.

[31] J.H. Gong, H.Z. Miao, B.J. Hu, Compositional dependence of hardness of (Ce,Y)$\mathrm{TZP} / \mathrm{Al}_{2} \mathrm{O}_{3}$ composites, Material Science and Engineering A 372 (2004) 207-212.

[32] Z. Shen, M. Johnsson, Z. Zhao, M. Nygren, Spark plasma sintering of alumina, Journal of the American Ceramic Society 85 (2002) 1921-1927.

\section{Figure captions:}

Figure 1. Microwave system designed for sintering and scheme of the cavity.

Figure 2. Density change as a function of microwave final sintering temperature.

Figure 3. The FE-SEM micrographs of nearly full dense $\mathrm{Al}_{2} \mathrm{O}_{3}-\mathrm{ZrO}_{2}$ samples sintered by MW at $1400^{\circ} \mathrm{C}: \mathrm{A} 5 \mathrm{Z}(\mathrm{a}), \mathrm{A} 10 \mathrm{Z}$ (b) and A15Z (c).

Figure 4. The FE-SEM micrographs of nearly full dense $\mathrm{Al}_{2} \mathrm{O}_{3}-\mathrm{ZrO}_{2}$ samples sintered by CS at $1400^{\circ} \mathrm{C}$ : A5Z (a), A10Z (b) and A15Z (c).

Figure 5. Influence of microwave sintering temperature on Vickers hardness of $\mathrm{Al}_{2} \mathrm{O}_{3}$ $\mathrm{ZrO}_{2}$ materials with different $\mathrm{ZrO}_{2}$ contents. 
Figure 6. Influence of microwave sintering temperature on fracture toughness of $\mathrm{Al}_{2} \mathrm{O}_{3^{-}}$ $\mathrm{ZrO}_{2}$ materials with different $\mathrm{ZrO}_{2}$ contents.

Figure 7. Influence of microwave sintering temperature on Young's modulus of $\mathrm{Al}_{2} \mathrm{O}_{3}$ $\mathrm{ZrO}_{2}$ materials with different $\mathrm{ZrO}_{2}$ contents. 


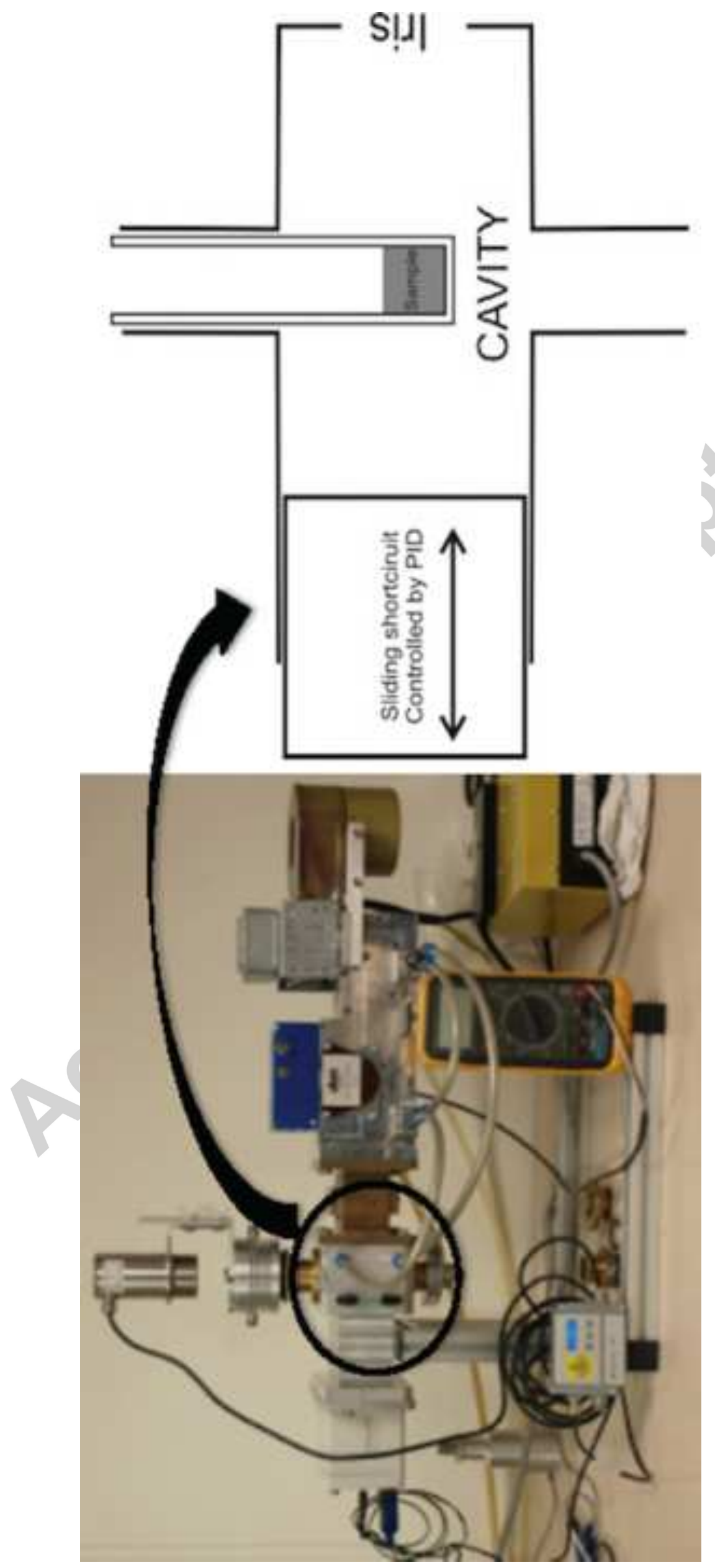

훈 


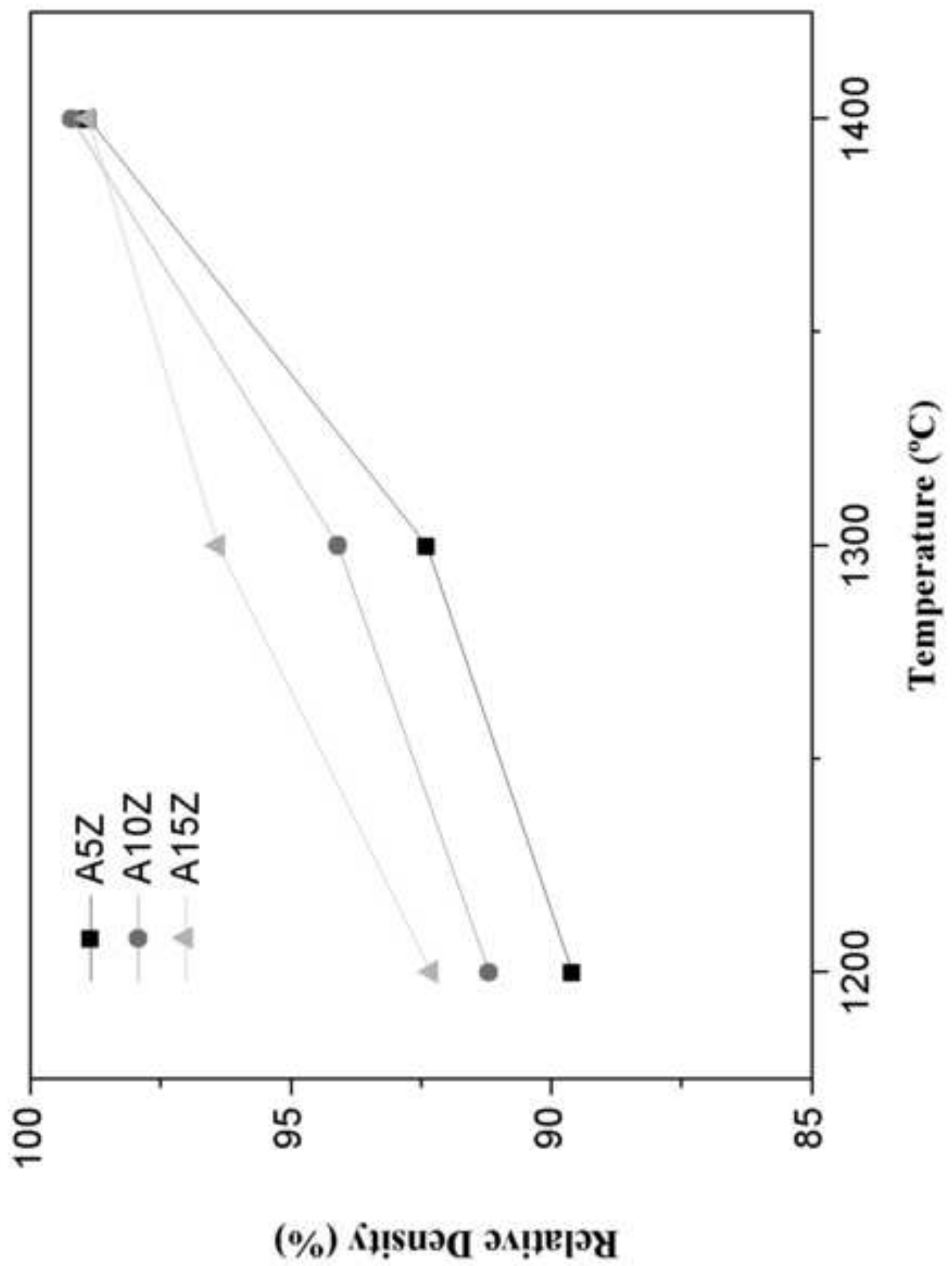

곤 

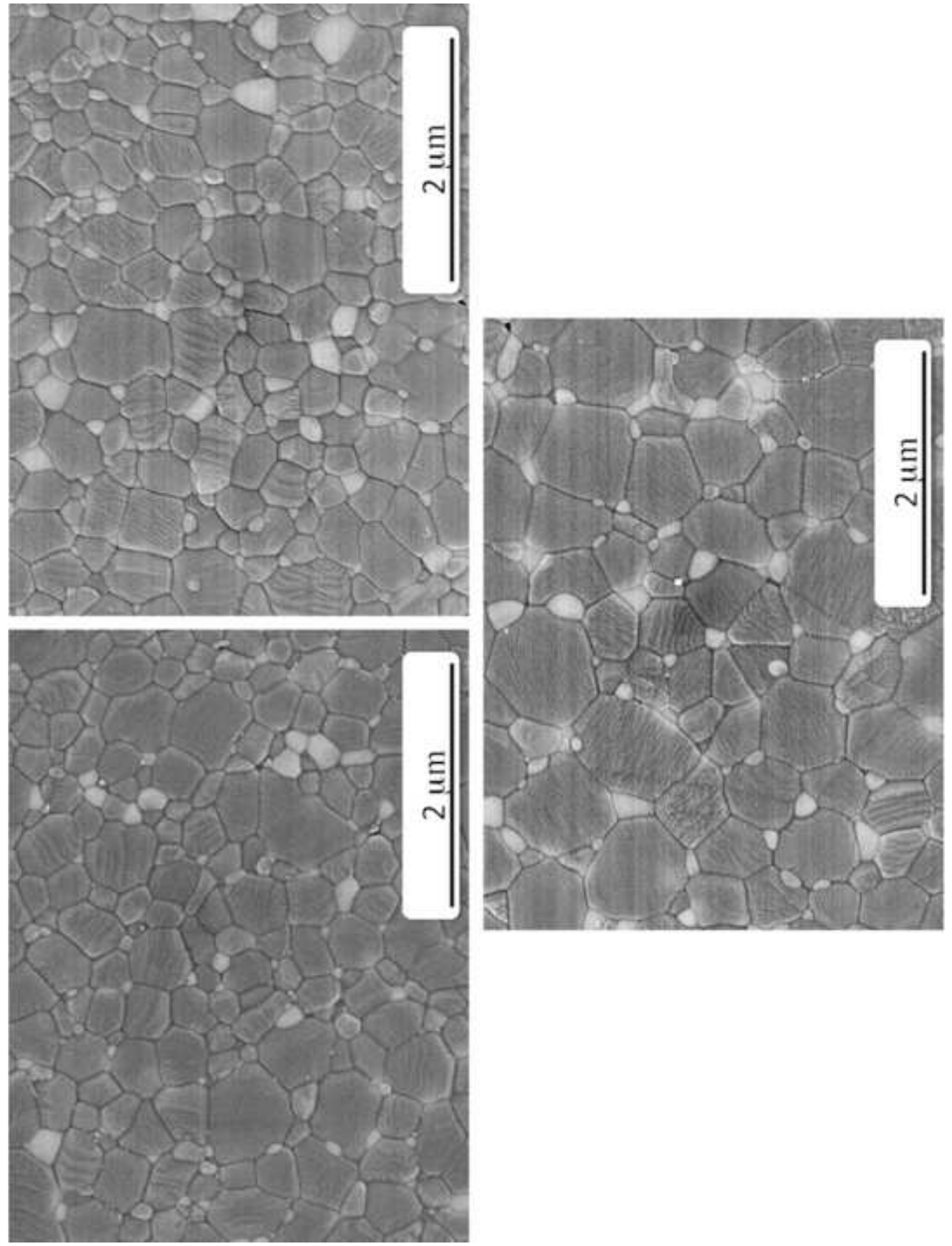

m 

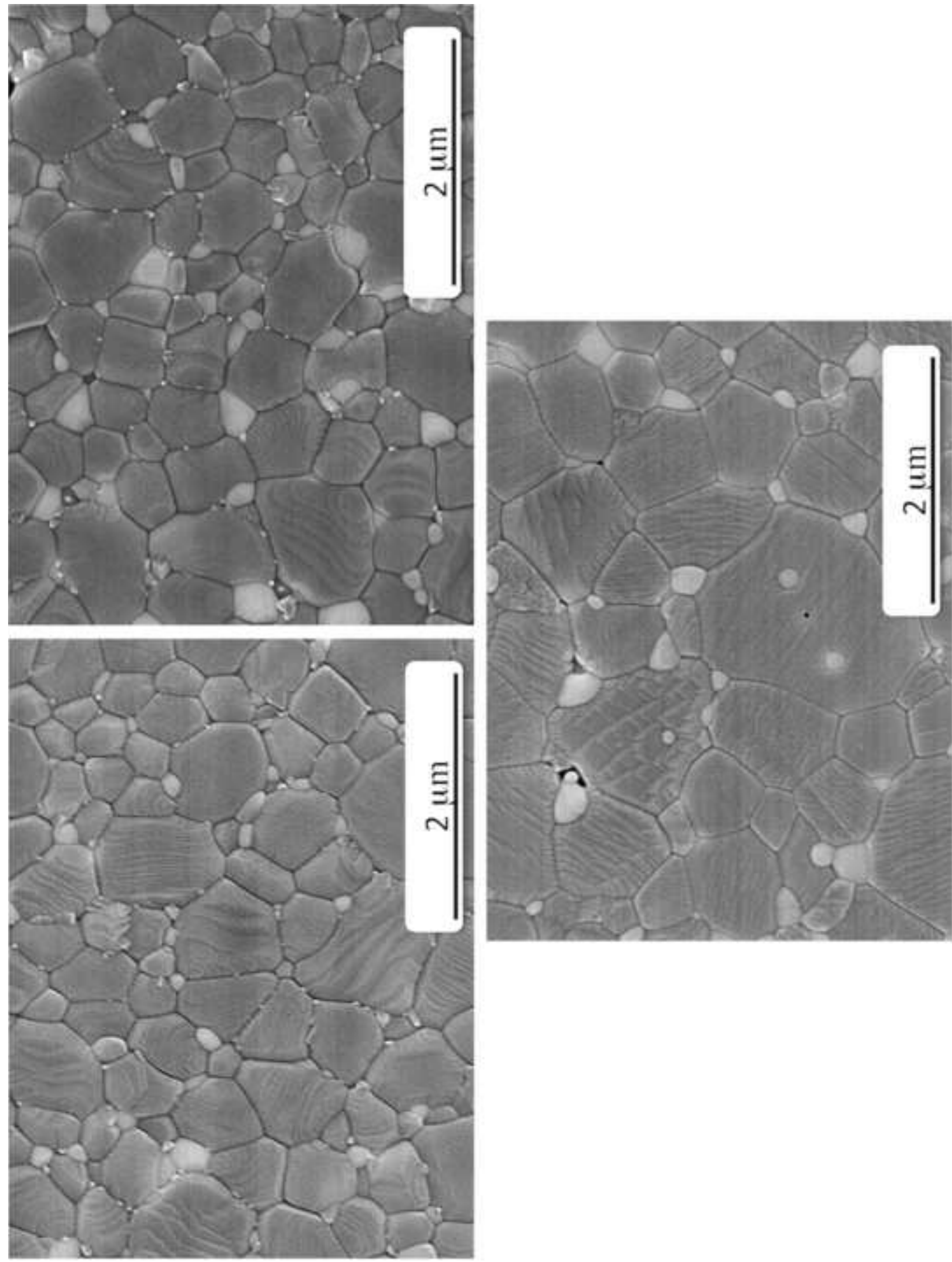

음 


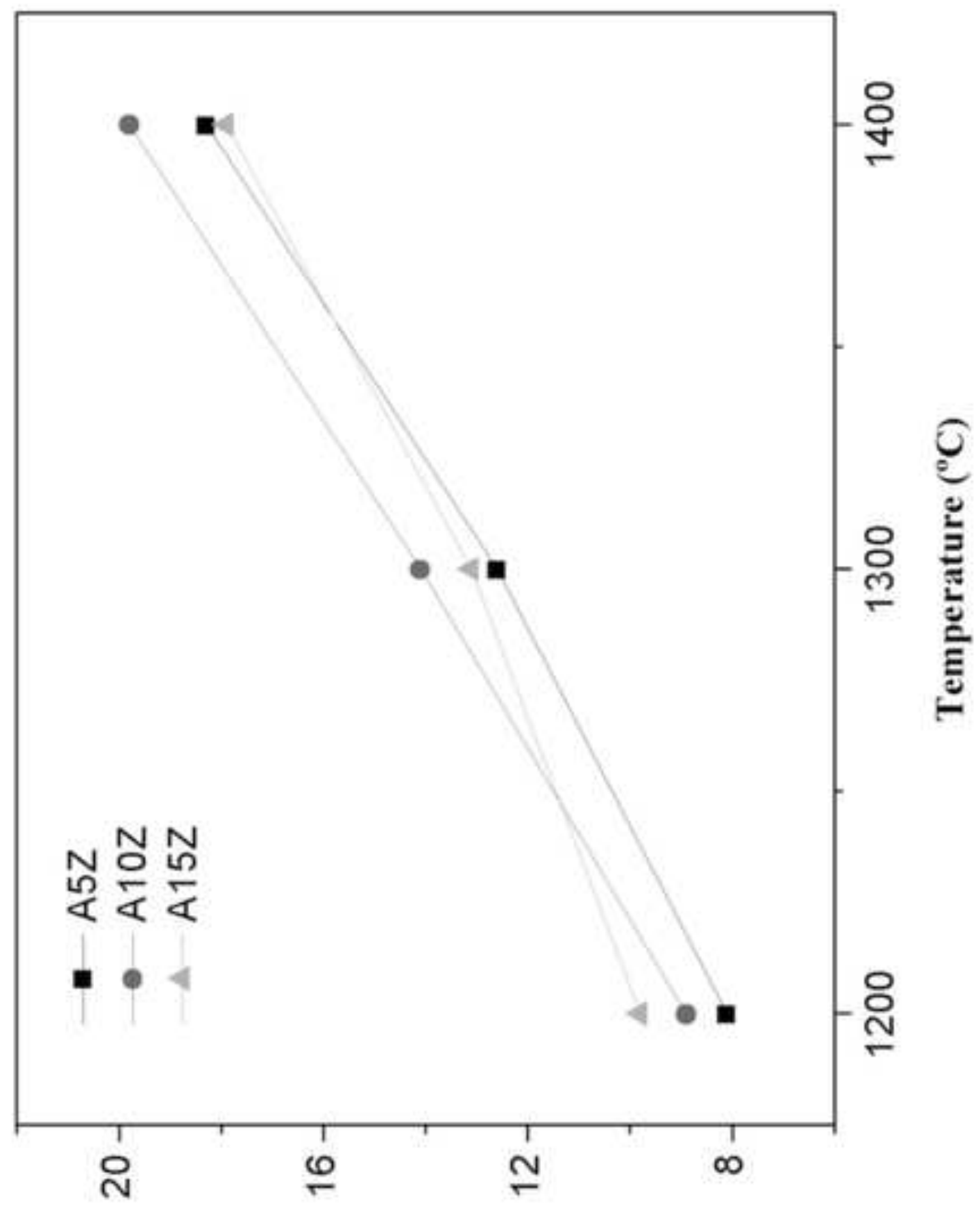

(в

온 


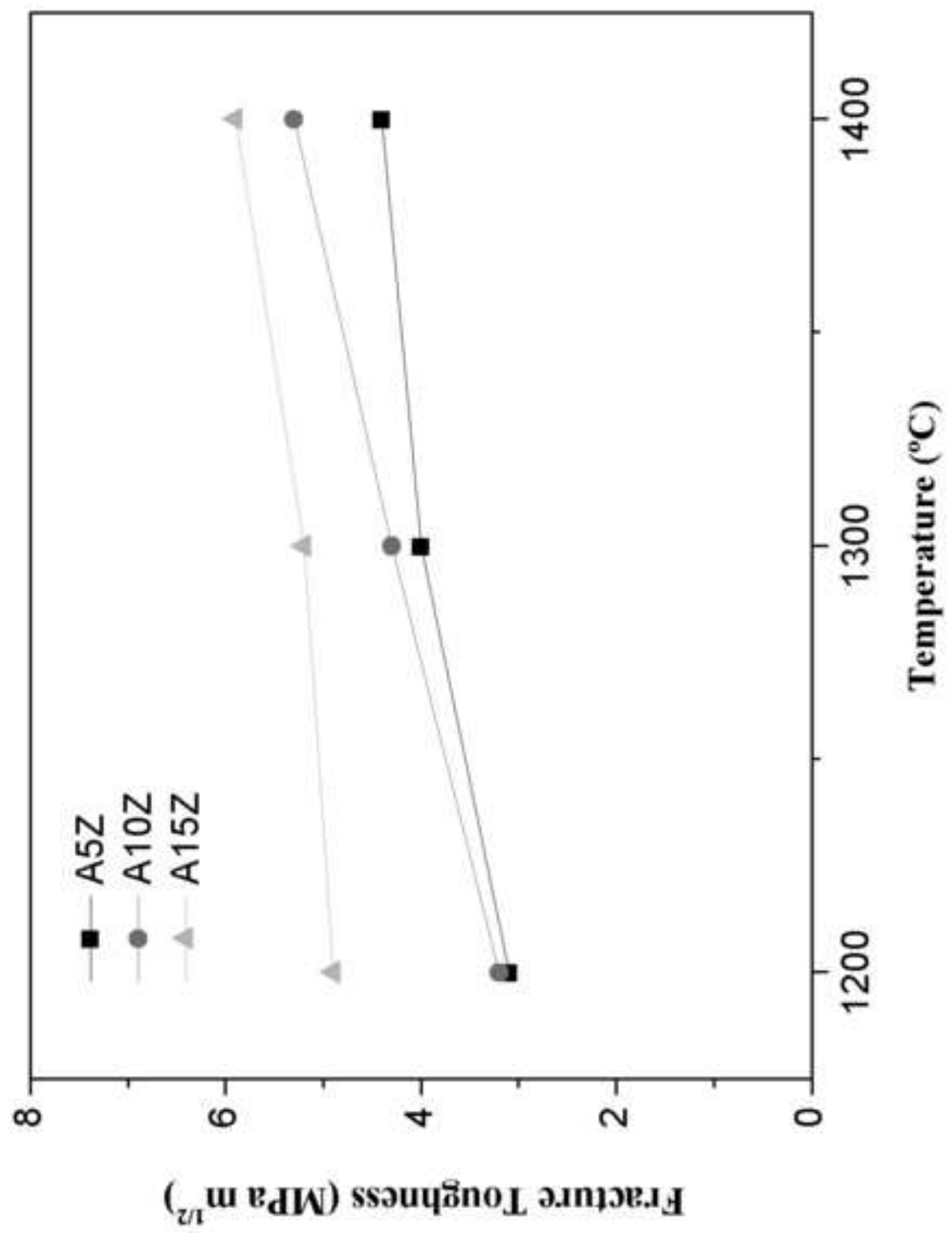

웅 


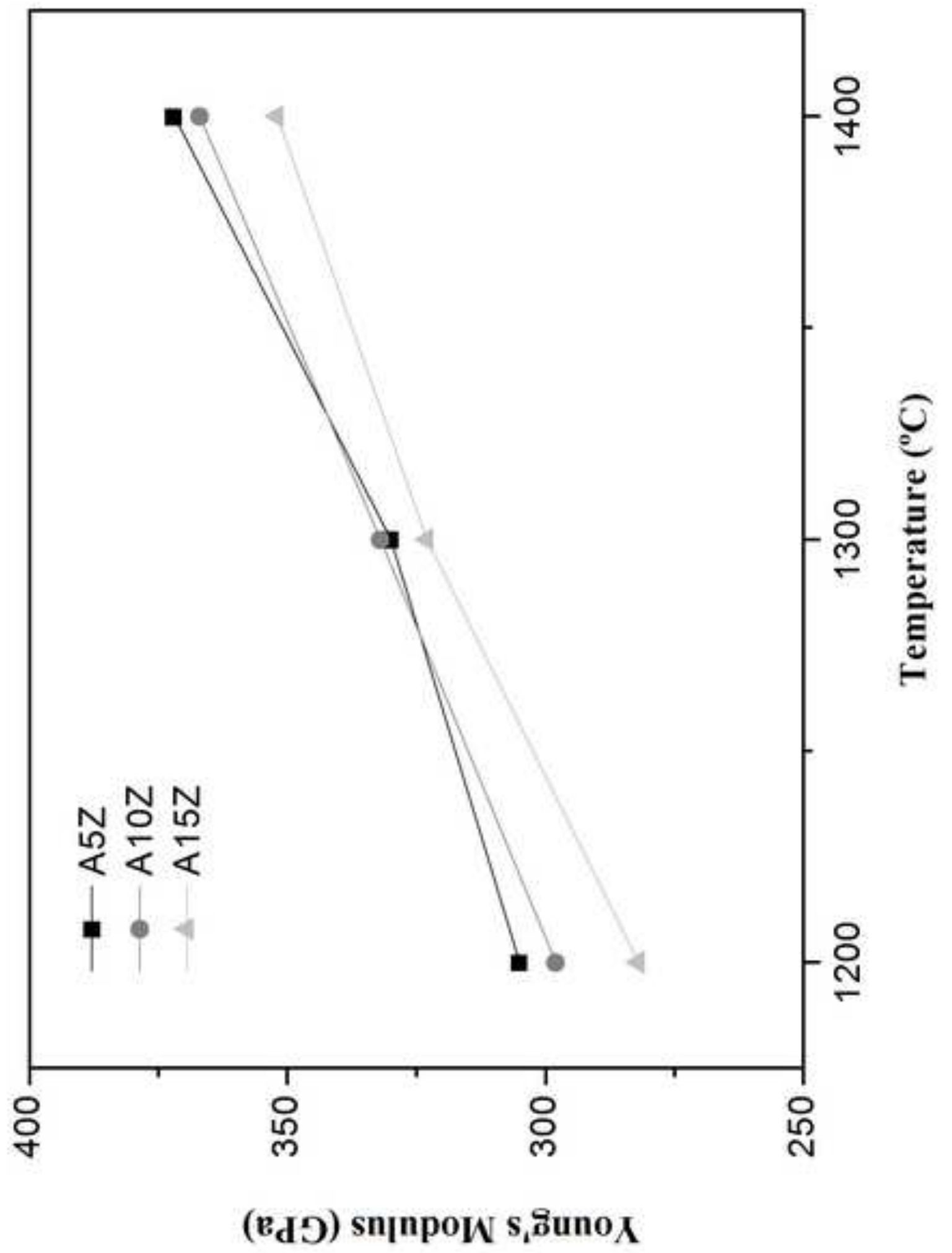

$\hat{}$ 